\title{
Evolution of the Deep Water in the Canadian Basin in the Arctic Ocean
}

\author{
M.-L. Timmermans* and Chris Garrett \\ Department of Physics and Astronomy, University of Victoria, Victoria, British Columbia, Canada
}

(Manuscript received 6 May 2005, in final form 28 October 2005)

ABSTRACT

\begin{abstract}
An overflow of magnitude $0.25 \mathrm{~Sv}\left(\mathrm{~Sv} \equiv 10^{6} \mathrm{~m}^{-3} \mathrm{~s}^{-1}\right)$ has been predicted to enter the Makarov Basin (part of the Canadian Basin in the Arctic Ocean) from the Eurasian Basin via a deep gap in the dividing Lomonosov ridge. The authors argue that this overflow does not ventilate the deep Makarov Basin (below $2400 \mathrm{~m}$ ) where the water is too warm and salty to be compatible with such a large cold fresh inflow. However, complete isolation of the homogeneous bottom layer of the Makarov Basin must be ruled out because changes there are too small to arise from more than a small fraction of the measured geothermal heat flux into the basin. A small cold fresh inflow of about $0.01 \mathrm{~Sv}$ from the Amundsen Basin seems to be required. This could occur if the gap in the dividing Lomonosov Ridge is shallower than previously thought. It could also occur if there is active mixing and dilution of the predicted overflow in the gap, leaving only a small fraction to descend into the deep Makarov Basin. Hydraulic theory and hydrographic observations are used to rule out any significant flow of dense water from the Makarov Basin into the deep Canada Basin, confirming previous hypotheses of isolation of the deep water in the Canada Basin.
\end{abstract}

\section{Introduction}

The Arctic Ocean (Fig. 1) contains two main basins, the Eurasian and Canadian, separated by the Lomonosov Ridge. Timmermans et al. (2005) have argued that the deepest waters of the Makarov Basin $(\mathrm{MB}$, a subbasin of the Canadian Basin) are being ventilated by a dense overflow from the adjacent Amundsen Basin ( $\mathrm{AB}$, a subbasin of the Eurasian Basin) via a gap in the Lomonosov Ridge (Fig. 2) at a depth of about $2400 \mathrm{~m}$. Using hydraulic theory and hydrographic observations they estimated the volume flow rate of the overflow to be $0.25 \mathrm{~Sv}\left(\mathrm{~Sv} \equiv 10^{6} \mathrm{~m}^{-3} \mathrm{~s}^{-1}\right)$.

Assuming that there is no significant mixing in the Lomonsov Ridge gap itself (though we return later to this possibility), we first investigate whether the properties of the deep water in the MB are compatible with this inflow, assuming that it penetrates into the deep water. Because the results of our analysis cast doubt on

\footnotetext{
* Current affiliation: Woods Hole Oceanographic Institution, Woods Hole, Massachusetts.
}

Corresponding author address: Mary-Louise Timmermans, Woods Hole Oceanographic Institution, MS 21, Woods Hole, MA 02453.

E-mail: mtimmermans@whoi.edu the magnitude of the overflow from the $\mathrm{AB}$ to the $\mathrm{MB}$, or at least the fraction of it that ventilates the deepest waters of the MB, we next consider other scenarios that could account for the existence and properties of the well-mixed bottom layer of the MB. We also examine whether water from the deep MB can flow through a gap between the Alpha and Mendeleyev Ridges (Fig. 1) and ventilate the deep Canada Basin (CB), contradicting the isolation scenario of Timmermans et al. (2003).

\section{Evolution of the deep water in the Makarov Basin}

a. Does the Amundsen Basin overflow reach the bottom of the Makarov Basin?

The evolution of the properties of MB deep water (below $2400 \mathrm{~m}$ ) depends upon whether the inflow of $\mathrm{AB}$ water remains sufficiently dense after mixing with lighter MB water to reach the bottom of the MB. An assessment of this issue can be made by considering Price and Baringer's (1994) analytical model of entrainment into a rotating hydraulically controlled flow over a sill. Their model assumes that entrainment occurs in a localized region just over the sill crest (in this case the Lomonosov Ridge) where the slope is maximal. The 


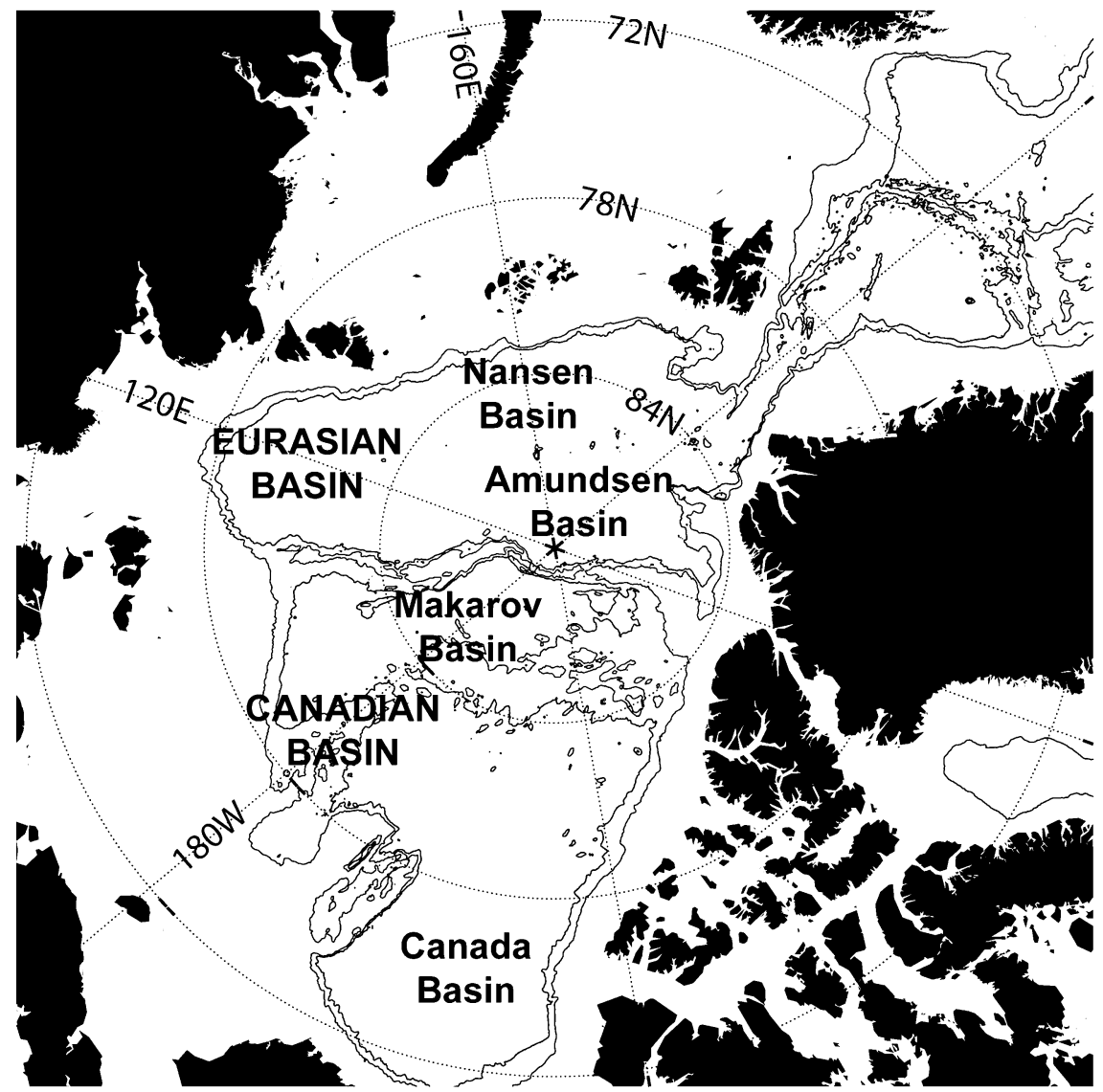

FIG. 1. Map of the Arctic Ocean. The Eurasian Basin (Nansen and Amundsen Basins) and the Canadian Basin are separated by the Lomonosov Ridge. The Canadian Basin is divided into the Makarov and Canada Basins by the Alpha and Mendeleyev Ridges (see also Fig. 6). The 1500- and 2400-m isobaths have been plotted using the IBCAO grid (information available online at www.ngdc.noaa.gov/mgg/bathymetry/arctic/).

model is based on the assumption that, unless the slope increases farther downstream, the density difference between the inflowing water and the ambient is sufficiently reduced at the entrainment site in the downstream basin that further significant entrainment is unlikely.

In the Price and Baringer (1994) model, as the overflow descends the slope, it undergoes a geostrophic adjustment and turns to the right, influenced by mixing and dissipation, and continues to flow at a small angle on the downhill sides of isobaths. The density difference $g^{\prime}$, the Coriolis parameter $f$, and the bottom slope $s$ are the important parameters that determine the current speed; the initial speed is only important in that it affects the volume transport. Entrainment occurs only if a geostrophic Froude number $F_{g}=U_{g} / \sqrt{g^{\prime} h_{g}}$ evaluated at the entrainment site is greater than 1 . Here, $U_{g}$ $=g^{\prime} s / f$ is the geostrophic velocity, and the flow thickness $h_{g}$ depends on how the flow spreads as a result of bottom stress. For the AB overflow over the
Lomonosov Ridge, $s \approx 0.03, g^{\prime} \approx 2 \times 10^{-4} \mathrm{~m} \mathrm{~s}^{-2}$, and $f=1.45 \times 10^{-4} \mathrm{~s}^{-1}$. Hence, $U_{g} \approx 0.04 \mathrm{~m} \mathrm{~s}^{-1}$. The initial height of the flow is about $700 \mathrm{~m}$ and the initial width $W_{s} \approx 900 \mathrm{~m}$ is chosen to give the transport of $0.25 \mathrm{~Sv}$ if the speed of the current is taken to be $0.4 \mathrm{~m} \mathrm{~s}^{-1}$, as for critical flow (i.e., the alongstream Froude number is 1 at the crest of the sill). Bottom stress causes the flow to widen downstream, with width $W=W_{s}+0.4 x$, where $x$ is the distance downstream from the sill. We estimate that the entrainment site is at $x \approx 7 \mathrm{~km}$ downstream from the sill, so that $W \approx 3700 \mathrm{~m}$ there. The continuity equation then gives the geostrophic current height $h_{g} \approx$ $1700 \mathrm{~m}$ [see Price and Baringer (1994) for further details of the model]. We thus find $F_{g} \approx 0.1 \leq 1$ for the flow over the Lomonosov Ridge from the $\mathrm{AB}$ to the MB. Hence, according to the model, there is no mixing and the product density equals the source density. Basically, the slope is not steep enough to induce a current strong enough to induce mixing. The overflow should then reach the bottom of the MB undiluted. 


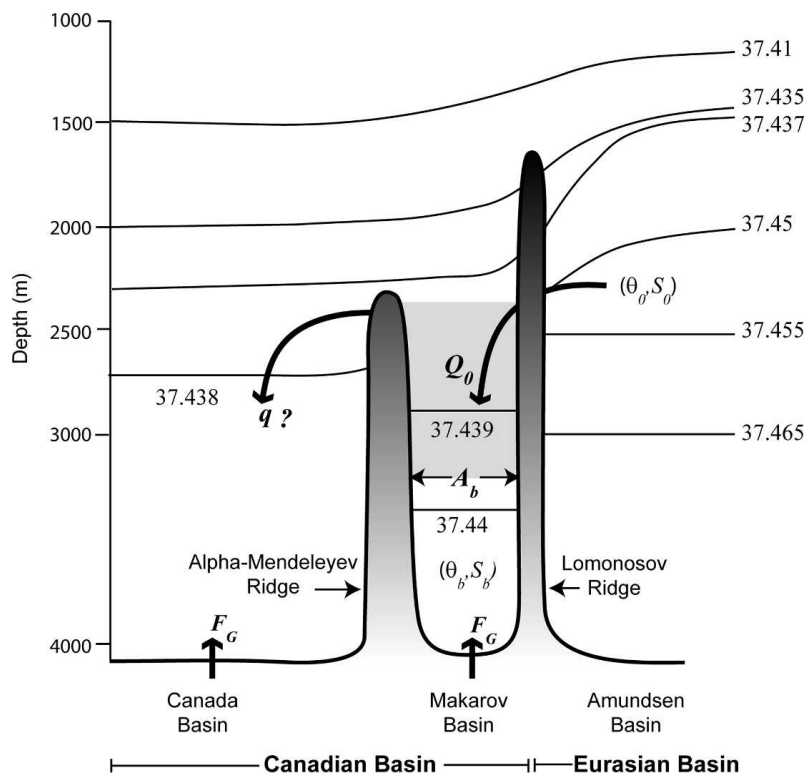

FIG. 2. Arctic section of potential density referenced to $2000 \mathrm{~m}$ $\left(\sigma_{2000}\right)$. The shaded region indicates the Makarov Basin below the deep gap in the Lomonosov Ridge, and above the homogeneous bottom layer in the Makarov Basin.

The large value of $h_{g}$ perhaps casts some doubt on the use of the Price and Baringer (1994) model here. Of further consequence may be downslope canyons that have been observed in the region of the gap (Cochran et al. 2006). Such canyons may channel some portion of the overflow, which could lead to the formation of eddies and, subsequently, enhanced mixing (see Chapman and Gawarkiewicz 1995). However, under the assumption that mixing is downstream of the gap itself, even if entrainment takes place as the source water descends into the MB, the stratification of the deep MB water column is very weak so bottom ventilation is still likely. This is apparent in the potential temperature $\theta$ (referenced to the surface) versus salinity $S$ plots for the two deep basins (Fig. 3). If water in the AB at $2400 \mathrm{~m}$ flows into the $\mathrm{MB}$ and mixes successively with deep water below $2400 \mathrm{~m}$, the product water is a linear mixture of this $\mathrm{AB}$ source and overlying $\mathrm{MB}$ water. Water that reaches the deep $\mathrm{MB}$ must lie somewhere in the sector defined by the deep $\mathrm{AB}$ source water and lines to the MB $\theta-S$ curve; if the product water has $\theta-S$ characteristics anywhere in the shaded region of the sector, it will be more dense than, or as dense as, MB bottom water.

We note that point $X$ in Fig. 3a corresponds to a mixture of 1 part $\mathrm{AB}$ source water and 6 parts $\mathrm{MB}$ water at the entrainment site for the Price and Baringer (1994) model. Thus, the volume flux would have to
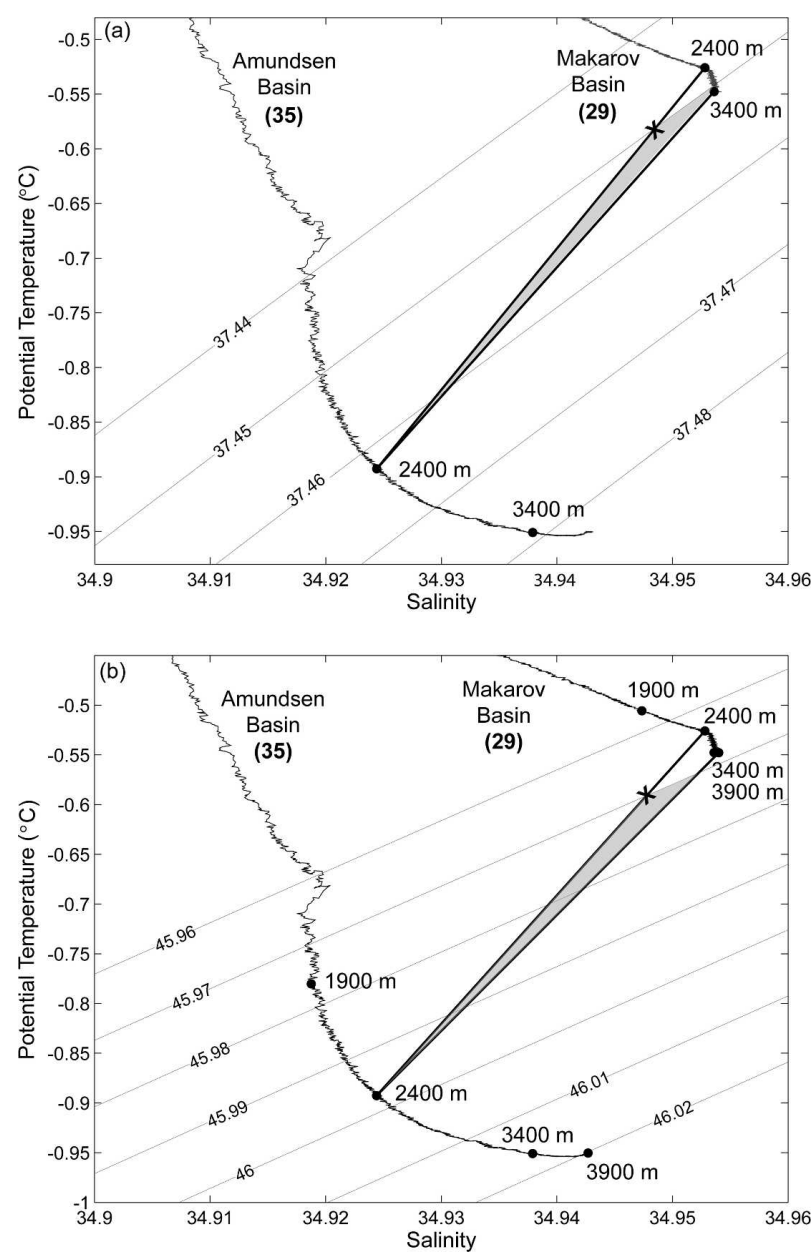

FIG. 3. Potential temperature $\left({ }^{\circ} \mathrm{C}\right.$; referenced to the surface) vs salinity in the Makarov and Amundsen Basins. CTD casts are from the Louis S. St-Laurent 1994 Arctic Ocean Section (AOS94) transect; the numbers correspond to stations shown in the inset map in Fig. 5. (a) Lines of constant density are $\sigma_{2000}$. (b) Lines of constant density are $\sigma_{3900}$.

increase by more than a factor of 7 to avoid descent of the inflow to the bottom of the MB. The effect of thermobaricity is shown to be minor by examining Fig. $3 \mathrm{~b}$ in which lines of $\sigma_{3900}$ (corresponding to the depth of the MB) are plotted. The tilting of the isopycnals with depth shows that the volume flux would have to increase by more than a factor of about 8 to avoid descent of the inflow to the bottom of the MB. According to the model, however, the volume flux increases by a factor of $F_{g}^{2 / 3}$, so that a value of 7 or 8 requires $F_{g} \approx 18-22$. This is two orders of magnitude greater than the estimated 0.1. Hence, unless there is strong mixing in the gap itself, it seems reasonable to formulate heat and salt budgets under the assumption that the deep MB water column is renewed by the $\mathrm{AB}$ overflow, probably undiluted. 


\section{b. Evolution of the homogeneous bottom layer in the Makarov Basin}

Profiles of potential temperature in the MB consistently show a homogeneous bottom layer deeper than about $3200 \mathrm{~m}$ (Fig. 4a). Salinity also appears to be uniform below this depth, although CTD accuracy limitations are apparent in the profiles (Fig. 4b).

We first consider the evolution of the homogeneous bottom layer, assuming that the cold fresh inflow $Q_{0} \approx$ $0.25 \mathrm{~Sv}$ from the $\mathrm{AB}$ reaches the bottom of the $\mathrm{MB}$ undiluted. The volume of the deep basin below $3200 \mathrm{~m}$ is $V_{b} \approx 0.11 \times 10^{6} \mathrm{~km}^{3}$. Hence, complete renewal of the homogeneous bottom layer would take place in $V_{b} / Q_{0}$ $\approx 14 \mathrm{yr}$. Based on this renewal time, we would expect to observe a cold, fresh layer occupying at least $3 / 4$ of the volume $V_{b}$ in about a decade, which we do not.

It is possible, however, that the geothermal heat input $F_{G}\left(\approx 50 \mathrm{~mW} \mathrm{~m}^{-2}\right)$ to the MB (Langseth et al. 1990) modifies at least the temperature of the injected water. If all of this geothermal heat was used in heating the new bottom water, its temperature would increase by an amount

$$
\Delta \theta=\frac{F_{G} A_{b}}{\rho c_{p} Q_{0}},
$$

where $A_{b} \approx 0.28 \times 10^{6} \mathrm{~km}^{2}$ is the area of the MB through a horizontal slice at the depth of the top of the homogeneous layer $(3200 \mathrm{~m}), \rho=1040 \mathrm{~kg} \mathrm{~m}^{-3}$ is the density, and $c_{p}=3900 \mathrm{~J} \mathrm{~kg}^{-1}{ }^{\circ} \mathrm{C}^{-1}$ is the specific heat capacity. This gives only $0.01^{\circ} \mathrm{C}$ for $\Delta \theta$, so that the inflow enters the $\mathrm{MB}$ with an average potential temperature $\theta_{0} \approx-0.90^{\circ} \mathrm{C}$ and salinity $S_{0} \approx 34.925$ and is heated up to $-0.89^{\circ} \mathrm{C}$, still cooler than the MB bottom water, which has $\theta_{b} \approx-0.55^{\circ} \mathrm{C}$ and salinity $S_{b} \approx 34.953$. Thus, the observed bottom layer is warmer and saltier than would be injected water modified by geothermal heating.

The vertical homogeneity of the bottom layer suggests that convective mixing is occurring. It is possible, in principal, that the geothermal heating, while small, is sufficient to cause destabilization. We compute $\alpha \Delta \theta$ and $\beta \Delta S=\beta\left(S_{0}-S_{b}\right)$, where $\alpha=-\rho^{-1} \partial \rho / \partial \theta$ and $\beta=$ $\rho^{-1} \partial \rho / \partial S\left[\alpha(\theta, p)=1.2 \times 10^{-4}{ }^{\circ} \mathrm{C}^{-1}\right.$ and $\beta(S, p)=7.6$ $\times 10^{-4} \mathrm{psu}^{-1}$ at $\theta=-0.5^{\circ} \mathrm{C}, S=34.9$, and pressure $p$ $=3000 \mathrm{dbar}]$, and find $|\alpha \Delta \theta|=1.2 \times 10^{-6}<|\beta \Delta S|=2.1$ $\times 10^{-5}$. Hence, the heating of the fresh influx is, in fact, not nearly enough to cause convective overturning. We cannot escape the expectation that we should observe a cold, fresh layer. We do not.

An alternative scenario to consider is one in which there is mixing of the $\mathrm{AB}$ overflow during its descent into the MB such that it has $\theta-S$ properties very close
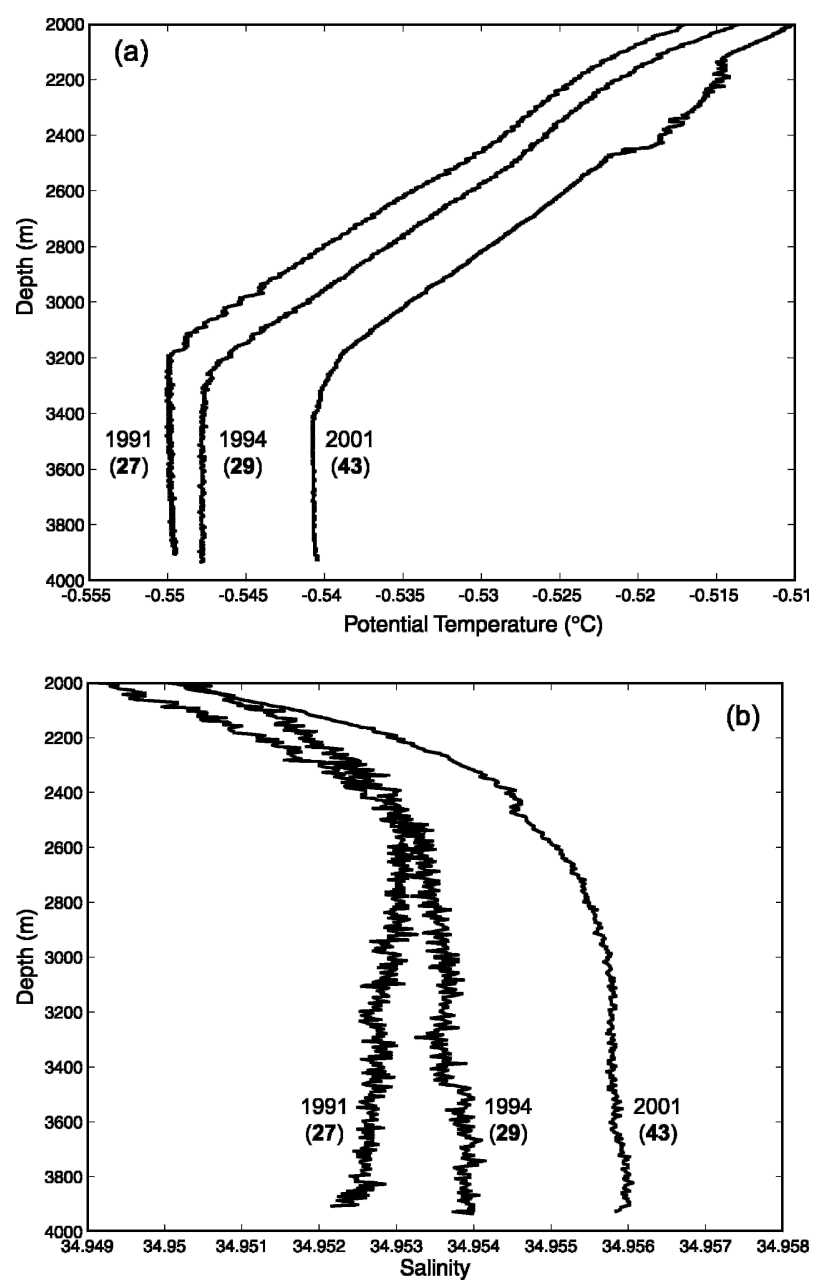

FIG. 4. (a) Potential temperature $\left({ }^{\circ} \mathrm{C}\right.$; referenced to the surface) and (b) salinity in the Makarov Basin from CTD profiles taken on 1991 and 2001 Oden expeditions and the Louis S. St-Laurent AOS94 transect. Station locations are shown in the inset map in Fig. 5.

to those of point $\mathrm{X}\left(\theta_{X}=-0.58^{\circ} \mathrm{C}, S_{X}=34.948\right)$ in Fig. 3 , with potential temperature very slightly less than at point $\mathrm{X}$ such that geothermal heating will cause convective overturning (i.e., the $\theta-S$ properties of the injection are $S_{i}=34.948$ and $\theta_{i}=-0.59^{\circ} \mathrm{C}$ ). Recall, such mixing would lead to a volume influx into the bottom layer of about $Q_{i} \approx 7 Q_{0}$. In this case, there would be no density change in the bottom layer and its potential temperature and salinity would evolve according to

$$
\frac{\partial \theta}{\partial t}=\frac{Q_{i}}{V_{b}}\left(\theta_{i}-\theta_{b}\right)+\frac{F_{G} A_{b}}{\rho c_{p} V_{b}}
$$

and

$$
\frac{\partial S}{\partial t}=\frac{Q_{i}}{V_{b}}\left(S_{i}-S_{b}\right),
$$


which yields $\partial \theta / \partial t \approx-0.02^{\circ} \mathrm{C} \mathrm{yr}^{-1}$ and $\partial S / \partial t \approx-0.003$ $\mathrm{yr}^{-1}$. The decadal cooling $\left(-0.2^{\circ} \mathrm{C}\right)$ and freshening $(-0.03)$ of the bottom layer would be easily observed in CTD profiles (Fig. 5), but it is not and we must rule out this scenario. We can similarly rule out scenarios in which the mixing is with water in the MB deeper than $2400 \mathrm{~m}$.

It thus seems that we cannot explain the MB homogeneous bottom layer in terms of a cold fresh overflow of $0.25 \mathrm{~Sv}$ from the AB. (Though, in section 3, we investigate a possible explanation for its structure.) It may be that the $\mathrm{AB}$ overflow does not reach the homogeneous bottom layer because it entrains too much lighter water as it descends into the MB (i.e., the bottom layer is sufficiently dense that it is isolated from $\mathrm{AB}$ water). Although we argued earlier that, even after mixing upon descent, an overflow of deep $A B$ water would likely reach the bottom of the MB, we next consider the possibility that $\mathrm{AB}$ water does not penetrate the bottom of the MB.

\section{c. Evolution of the Makarov Basin deeper than $2400 \mathrm{~m}$}

We consider the evolution of the volume $V_{t}$ of $\mathrm{MB}$ water (the shaded region in Fig. 2) below $2400 \mathrm{~m}$ and above the homogeneous bottom layer. This volume is $V_{t} \approx 0.15 \times 10^{6} \mathrm{~km}^{3}$, so that complete renewal of this volume by an influx of $0.25 \mathrm{~Sv}$ would take place in about $20 \mathrm{yr}$. This flushing would produce decreases in temperature and salinity by at least $0.01^{\circ} \mathrm{C}$ and 0.01 , respectively, and these are not observed (Fig. 5).

This lack of evidence for a cold fresh injection into the deep MB (both the homogeneous bottom layer and the region above it below $2400 \mathrm{~m}$ ) leads us in section $3 \mathrm{~b}$ to question the duration, path, and character of the overflow postulated by Timmermans et al. (2005). It is conceivable that the deep MB is isolated.

\section{Interpretation of the homogeneous bottom layer in the Makarov Basin}

\section{a. Is the bottom layer isolated?}

If we assume that the $\mathrm{MB}$ homogeneous bottom layer is isolated, and if the geothermal heat influx to the MB remained in the bottom layer, an increase in thickness or temperature of this layer would result. If all of the geothermal heat remains in the bottom layer, the potential temperature $\theta$ of this layer, of thickness $H \approx$ $800 \mathrm{~m}$, evolves according to $d \theta / d t=F_{G} /\left(\rho c_{p} H\right)$. This gives a potential temperature increase of about $0.0005^{\circ} \mathrm{C} \mathrm{yr}^{-1}$, or about $0.0045^{\circ} \mathrm{C}$ between 1991 and 2001. We estimate the maximum heating of the homo-
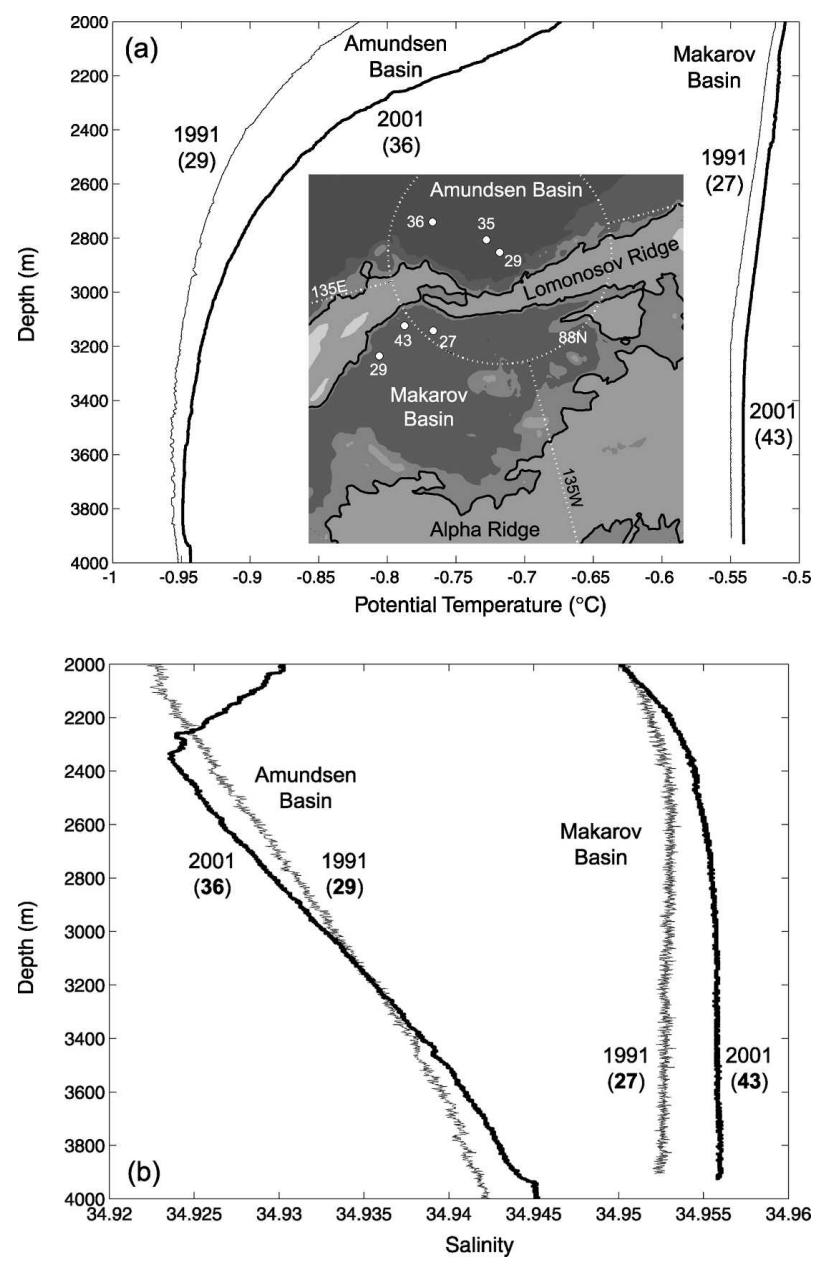

FIG. 5. (a) Potential temperature and (b) salinity profiles in the Amundsen and Makarov Basins from the 1991 (thin lines) and 2001 (thick lines) Oden expeditions. Station locations are shown in the inset map, which shows the 2400-m isobath.

geneous bottom layer that would go undetected in CTD profiles to be about $1 \times 10^{-4 \circ} \mathrm{C} \mathrm{yr}^{-1}$, corresponding to a heat flux of $F_{G} \approx 10 \mathrm{~mW} \mathrm{~m}^{-2}$.

We would also expect that such heating would lead to steps in temperature and salinity at the top of the bottom layer. However, the salinity gradient has only a small effect on the density profile above this bottom layer, so that geothermal heating would result in a thickening of the bottom layer at a rate of $(d \theta / d t) /$ $(\overline{\partial \theta / \partial z})$, where $\overline{\partial \theta / \partial z} \approx-2 \times 10^{-5 \circ} \mathrm{C} \mathrm{m}^{-1}$. This would yield an approximately $250-\mathrm{m}$ increase in thickness of the homogeneous layer over a decade. There is no evidence for bottom-layer thickening (Fig. 4) and we must rule out such a scenario. We estimate the maximum thickness increase that may go undetected to be about $5 \mathrm{~m} \mathrm{yr}^{-1}$, again corresponding to a heat flux of $F_{G} \approx 10 \mathrm{~mW} \mathrm{~m}^{-2}$. 
Hence, we can conclude that no more than about $1 / 5$ of the total geothermal heat remains in the bottom layer, as seen by an increase in temperature or thickness of this layer. It is possible that a lateral circulation is set up in this layer and most of the geothermal heat is escaping at basin boundary regions of higher mixing, as in the deep Canada Basin (Timmermans et al. 2003). However, unlike in the deep Canada Basin, warmer water overlies the homogeneous bottom layer in the $\mathrm{MB}$, implying a heat gain, rather than heat loss, though additional deep MB boundary profiles of temperature and salinity are needed to confirm this.

We also note that a much smaller geothermal heat flux into the MB than measurements indicate is unlikely, since Langseth et al. (1990) show that the measured geothermal heat flux of $50 \mathrm{~mW} \mathrm{~m}{ }^{-2}$ agrees well with the predicted heat flux for a cooling lithosphere. Thus, a scenario of bottom-layer isolation can be ruled out.

\section{b. Assessment of the Amundsen Basin overflow}

The possibility remains that the volume flux of $A B$ water that reaches the MB homogeneous bottom layer is smaller than $0.25 \mathrm{~Sv}$. We can estimate a flow of $\mathrm{AB}$ water into the deep MB that provides a realistic explanation of the, likely convecting, MB homogeneous bottom layer. Suppose that geothermal heating is sufficient to raise the temperature of the inflow from $\theta_{0} \approx$ $-0.90^{\circ} \mathrm{C}$ to the present bottom temperature $\theta_{b} \approx$ $-0.55^{\circ} \mathrm{C}$. Then, $\Delta \theta \approx 0.35^{\circ} \mathrm{C}$, and (1) requires an influx of about $0.01 \mathrm{~Sv}$, giving a 350-yr renewal time for the homogeneous bottom layer. This renewal time is at least approximately consistent with $\Delta^{14} \mathrm{C}$ isolation age estimates of Schlosser et al. (1997) who deduced that the MB bottom water has been in isolation for about $450 \mathrm{yr}$, about $200 \mathrm{yr}$ longer than the deep waters of the AB. For an influx of about $0.01 \mathrm{~Sv}$, the geothermal heating in the MB would be sufficient to cause convection and the salinity $S$ of the volume $V_{b}$ would then evolve according to (3), which gives $\partial S / \partial t \approx-0.00008$ $\mathrm{yr}^{-1}$. This estimated freshening of the bottom layer is within CTD accuracy limitations. It is possible that we do not observe a step at about $3200 \mathrm{~m}$ in the salinity profile due to small diffusion of salt from the overlying water. Note that an overflow of up to $0.02 \mathrm{~Sv}$ would still be compatible with convection, but implies $\partial \theta / \partial t \approx$ $-0.001{ }^{\circ} \mathrm{C} \mathrm{yr}^{-1}$ and $\partial S / \partial t \approx-0.00016 \mathrm{yr}^{-1}$ in the bottom layer.

A smaller overflow would exist if the geometry of the gap in the Lomonosov Ridge is different than suggested by the International Bathymetric Chart of the Arctic Ocean (IBCAO) bathymetry. The presumed 2400-m gap in the Lomonosov Ridge occurs between bathymetric survey lines and may partially be the result of inter- polation in contouring (Cochran et al. 2006); more bathymetric observations are needed to establish its exact depth. A deep gap of about $1900 \mathrm{~m}$ in the Lomonosov Ridge (about $500 \mathrm{~m}$ shallower than shown by IBCAO bathymetry) would yield an overflow of magnitude $0.01 \mathrm{~Sv}$. In the same manner as for a $0.25-\mathrm{Sv}$ overflow, we calculate the geostrophic Froude number for a $0.01-\mathrm{Sv}$ overflow from the $\mathrm{AB}$ to the $\mathrm{MB}$. For a sill depth of $1900 \mathrm{~m}$, the initial height of the overflow is 200 $\mathrm{m}$ and $g^{\prime}=5 \times 10^{-5} \mathrm{~m} \mathrm{~s}^{-2}$, giving an initial width of 500 $\mathrm{m}$ if the speed of the current is taken to be $0.1 \mathrm{~m} \mathrm{~s}^{-1}$, as for critical flow at the crest of the sill. The geostrophic velocity and height are now about $0.01 \mathrm{~m} \mathrm{~s}^{-1}$ and 300 $\mathrm{m}$, respectively. This gives $F_{g} \approx 0.1 \leq 1$, and hence, according to the Price and Baringer (1994) model, there would be no mixing and the overflow should reach the bottom of the MB undiluted. Taking thermobaricity into account, $0.01 \mathrm{~Sv}$ of water from $1900 \mathrm{~m}$ in the $\mathrm{AB}$ can reach the bottom provided it does not entrain more than an equal volume of ambient water (see Fig. 3b).

The density profiles shown in Timmermans et al. (2005) show no significant changes in the $A B$ over the decade of available measurements, suggesting that a continuous, albeit smaller, overflow is more likely than an intermittent overflow. On the other hand, Woodgate et al. (2001) present year-long time series of temperature and salinity that indicate a small episodic flow of Eurasian Basin water into the Canadian Basin at about 1700-m depth. Future sustained observations may yet show that such episodic flows are also found deeper in the water column.

Another possibility, also mentioned in section 1, is that there is very active mixing in the gap in the Lomonosov Ridge. Further, it could be that the lighter mixed water from the gap aligns itself along a shallower isobath and traverses the basin boundary rather than descending into the deep MB. Additional hydrographic data are needed to investigate these possibilities.

While we have formulated a possible scenario for the deep MB, the difference in thermohaline structure between the deep MB and the deep Canada Basin (CB) implies different deep basin mixing histories and evolution of the temperature and salinity. This suggests that these two subbasins of the Canadian Basin need to be treated independently. Next, we investigate whether there is renewal of the deep CB from the MB.

\section{Evolution of the deep water in the Canada Basin}

The Canadian Basin is divided by the approximately 2200-m-deep Alpha and Mendeleyev Ridges into the 


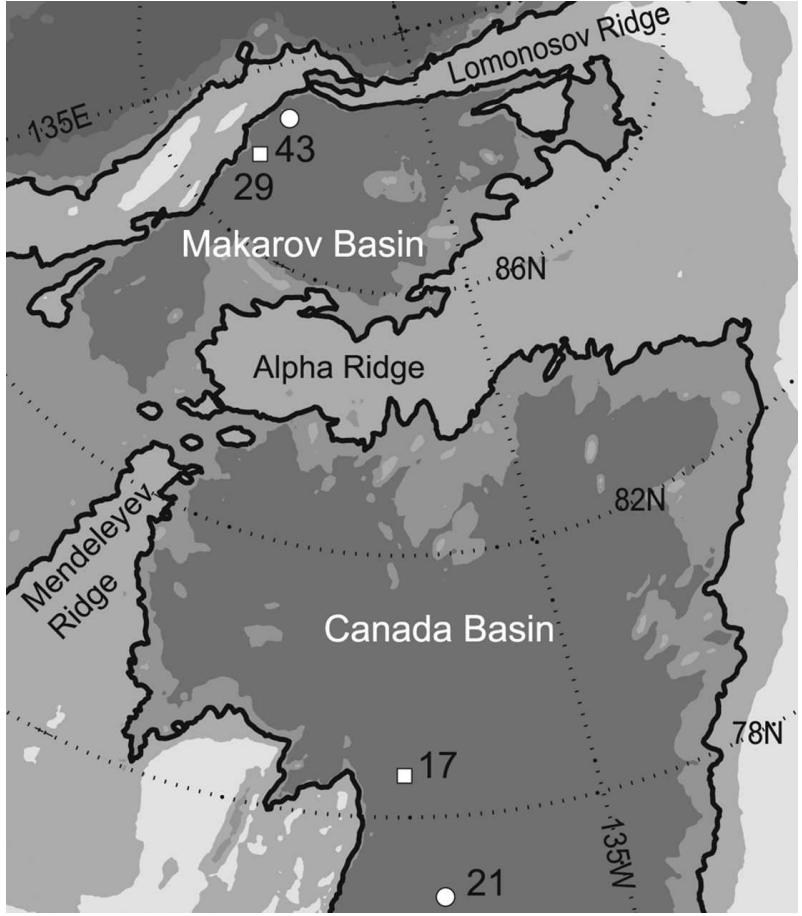

FIG. 6. Map of the Makarov and Canada Basins. The Alpha and Mendeleyev Ridges separate the two basins. The detailed Arctic bathymetry (Jakobsson et al. 2000) and locations of CTD profiles taken on the 2001 Oden expedition, and 1993, 1994, and 2002 Louis S. St-Laurent expeditions used in this study are shown. Matching symbols indicate cast pairs used in the volume flow-rate calculations (see Fig. 9). The thick black line is the 2400-m contour.

Makarov and Canada Basins (Fig. 6). This barrier is presumably one reason why the deep temperature and salinity properties in the two basins are so different (Fig. 7). Nonetheless, the latest International Bathymetrical Chart of the Arctic Ocean (IBCAO; Jakobsson et al. 2000) indicates a gap between these ridges where deep-water exchange between the $\mathrm{MB}$ and $\mathrm{CB}$ is possible. The gap is located near $83^{\circ} \mathrm{N}, 175^{\circ} \mathrm{W}$, with a sill depth of approximately $2400 \mathrm{~m}$ (Fig. 6). We need to consider whether denser water from the $\mathrm{MB}$ can flow through this gap and penetrate the deep CB.

\section{Is the deep Canada Basin isolated?}

Profiles of potential density (Fig. 8) in the MB and the $\mathrm{CB}$ show that between about 2400 and $2600 \mathrm{~m}$ the densities of the $\mathrm{MB}$ and the $\mathrm{CB}$ are similar. Thus, even if a gap deeper than $2400 \mathrm{~m}$ exists, exchange between the two basins would not affect the deep waters of either. However, below about $2600 \mathrm{~m}$ the MB water is dense enough that if it could enter the $\mathrm{CB}$ it could ventilate the bottom water there. In view of the uncertainty in the IBCAO bathymetry, we consider the pos-
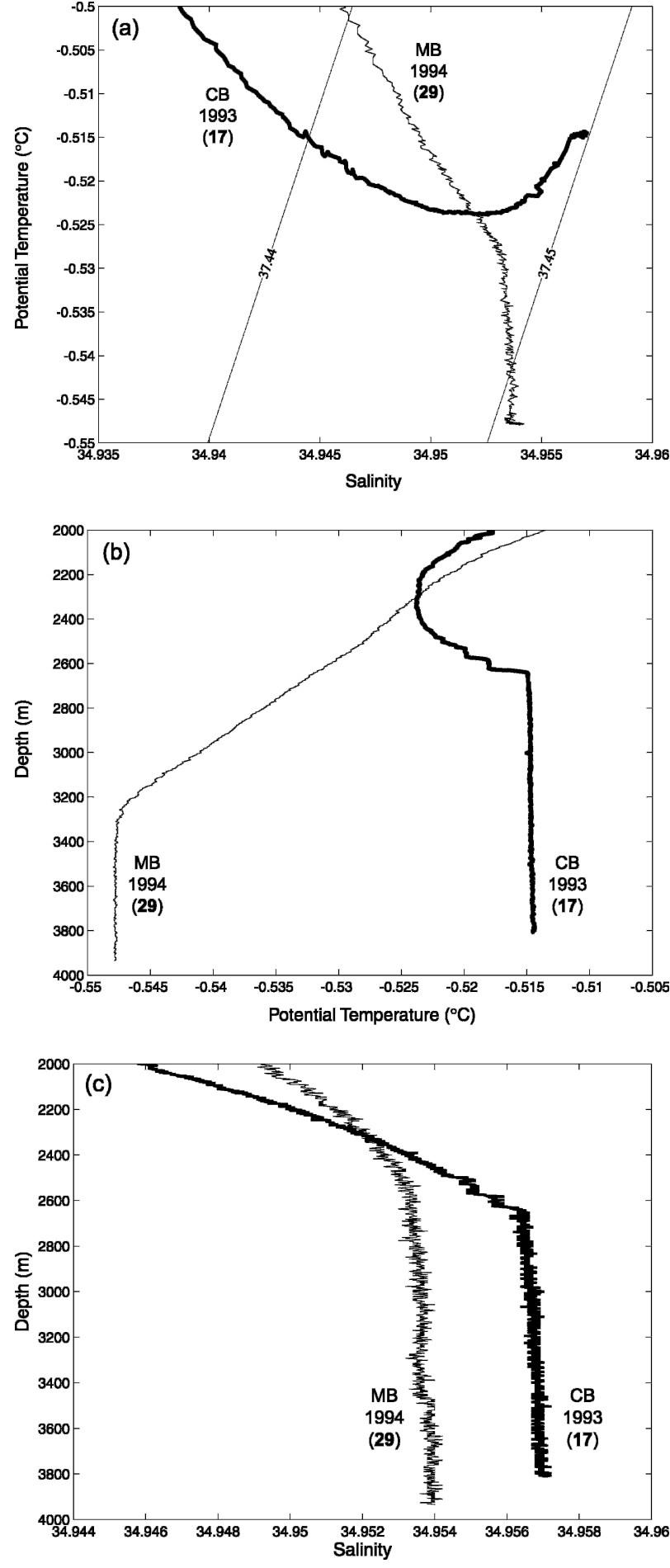

FIG. 7. (a) Salinity vs potential temperature $\left({ }^{\circ} \mathrm{C}\right.$; lines of constant density are $\left.\sigma_{2000}\right)$; (b) potential temperature $\left({ }^{\circ} \mathrm{C}\right)$ and $(\mathrm{c})$ salinity vs depth (m) in the Makarov and Canada Basins. Stations are shown in Fig. 6. 

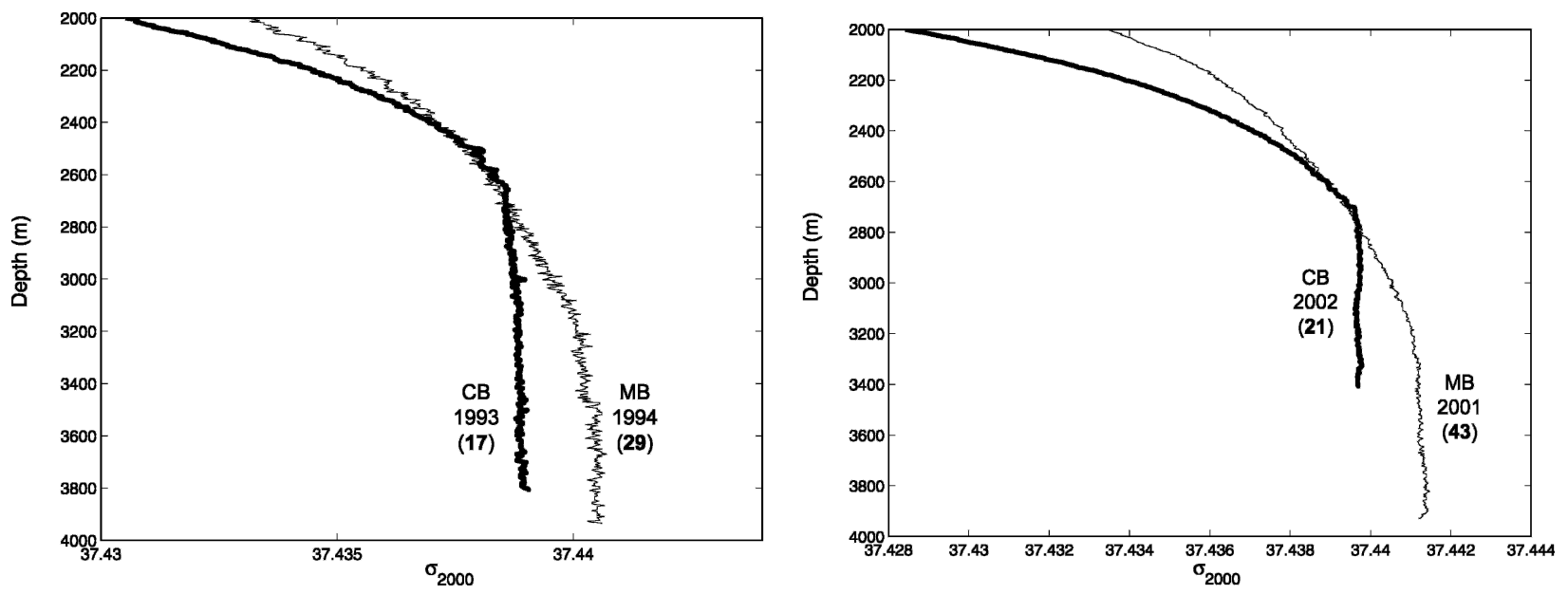

Fig. 8. Potential density referenced to 2000-m $\left(\sigma_{2000}\right)$ profiles from stations shown in Fig. 6.

sibility that a gap deeper than $2400 \mathrm{~m}$ exists, and use hydraulic theory and observations to estimate the magnitude of a flow from the MB to the CB.

The flow of dense water through any gap, which acts as a sill, is likely to be hydraulically controlled and influenced by the earth's rotation. We use a weir formula (Whitehead et al. 1974) to relate the volume flow rate $q$ of dense $(\rho+\Delta \rho)$ water in the deep upstream basin to the depth $h_{u}$, at which density profiles in the up- and downstream basins diverge, above the sill. That is,

$$
q=\frac{g^{\prime} h_{u}^{2}}{2 f}
$$

where $g^{\prime}=g \Delta \rho / \rho$ and $f$ is the Coriolis parameter $(f=$ $1.43 \times 10^{-4} \mathrm{~s}^{-1}$ ). Equation (4) holds in the strong rotation limit, for channels wider than the Rossby deformation radius $R=\sqrt{2 g^{\prime} h_{u} / f^{2}}$. If $h_{u} \approx 100 \mathrm{~m}$ and $g^{\prime} \approx$ $1.2 \times 10^{-5} \mathrm{~m} \mathrm{~s}^{-2}, R \approx 350 \mathrm{~m}$, much less than the width of tens of kilometers of the opening at the depth $h_{u}$.

To estimate the amount $\Delta \rho$ by which the flow over the sill is denser than the $\mathrm{CB}$ deep water, we compare density profile pairs from the $\mathrm{MB}$ and $\mathrm{CB}$ at the sill depth (Fig. 8). The computed volume flow rate is shown in Fig. 9 as a function of sill depth $h_{s}$. Figure 9 implies that there must be a significantly deeper (about $3200 \mathrm{~m}$ deep) gap in the ridge if the volume inflow from the $\mathrm{MB}$ is to be even $0.01 \mathrm{~Sv}$. Although the IBCAO bathymetry is not exact, and we might expect gaps up to a few hundred meters deeper, a gap that is $800 \mathrm{~m}$ deeper than shown by the bathymetry is very unlikely. Hence, we exclude the possibility at present of any significant influx of deep MB water into the deep CB (it would take as long as $3100 \mathrm{yr}$ for an inflow as small as $0.01 \mathrm{~Sv}$ to ventilate the deep CB, taking its volume to be about $1 \times 10^{6} \mathrm{~km}^{3}$ ).

\section{Summary and fundamental observational questions}

The analysis presented here has first led us to contradict a scenario, suggested by the rudimentary model of Timmermans et al. (2005), in which a deep AB overflow of magnitude $0.25 \mathrm{~Sv}$ ventilates the MB below 2400 $\mathrm{m}$. Second, we have excluded the possibility that the MB bottom layer is completely isolated, and shown that it instead may be ventilated by a volume inflow from the Amundsen Basin that is about $0.01 \mathrm{~Sv}$. Third, observations have allowed us to speculate that ongoing renewal of the deep Canada Basin is unlikely and the most likely scenario is that the present Canada Basin deep water is the result of a renewal event in the past [in agreement with Timmermans et al. (2003)]. Evi-

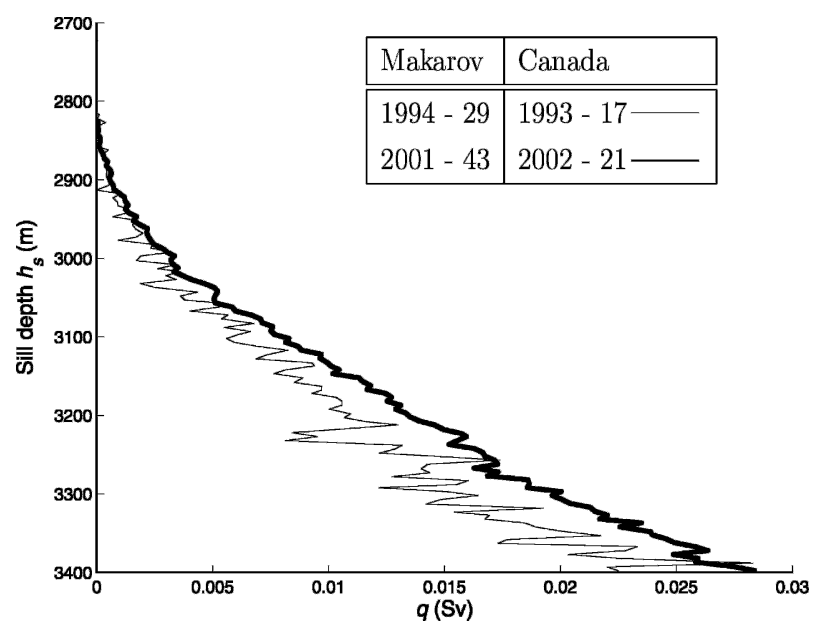

FIG. 9. Volume flow rate $q$ from the MB to the $\mathrm{CB}$ as a function of the sill depth $h_{s}$. Here, $q$ is calculated from (4), taking the depth at which the density profile pairs diverge to be $2600 \mathrm{~m}$. 
dence for these points is clearly limited by the spatial and temporal coverage of deep basin measurements and CTD accuracies. Further, we have not addressed the likelihood of alternative sources for renewal of the Makarov Basin deep water. For example, the inflow of dense shelf water, caused by ice growth there and subsequent dense brine formation, may also contribute to the ventilation.

Future long-term observations are required to make predictions regarding the future of the deep Makarov and Canada Basins. Sustained hydrographic observations are required in all of the deep basins of the Arctic Ocean to establish whether the MB is cooling and freshening and to find out what changes are occurring in both the deep AB upstream and the CB downstream. Additional observations (including bathymetry and, ideally, velocity) in the sites of possible overflows (the purported gap in the Lomonosov Ridge and between the Alpha and Mendeleyev Ridges) are also needed to constrain our present hypotheses and to help to guide future theoretical models of deep Arctic ventilation.

Acknowledgments. Data used here were collected by the support teams of 1991-2002 Arctic expeditions aboard the Swedish polar class icebreaker Oden, and the CCGS Louis S. St-Laurent (supported by the Fisheries and Oceans Canada Strategic Science Fund, Institute of Ocean Sciences). We thank the captains and crew of these vessels. We also thank Robin Muench and two anonymous reviewers for their valuable comments and suggestions. The support of the U.S. Office of Naval Research and the Natural Sciences and Engineering Research Council, Canada, is also gratefully acknowledged.

\section{REFERENCES}

Chapman, D. C., and G. Gawarkiewicz, 1995: Offshore transport of dense shelf water in the presence of a submarine canyon. J. Geophys. Res., 100, 13 373-13 387.

Cochran, J. R., M. H. Edwards, and B. J. Coakley, 2006: Morphology and structure of the Lomonosov Ridge, Arctic Ocean. Geochem. Geophys. Geosyst. , 7, Q05019, doi:10.1029/ 2005 GC001114.

Jakobsson, M., N. Cherkis, J. Woodward, B. Coakley, and R. Macnab, 2000: A new grid of Arctic bathymetry: A significant resource for scientists and mapmakers. Eos, Trans. Amer. Geophys. Union, 81, 89, 93, 96.

Langseth, M. G., A. H. Lachenbruch, and B. V. Marshall, 1990: Geothermal observations in the Arctic region. The Geology of North America, The Arctic Ocean Region, A. Grantz, L. Johnson, and J. F. Sweeney, Eds., Geological Society of America, 133-151.

Price, J. F., and M. O. Baringer, 1994: Outflows and deep water production by marginal seas. Progress in Oceanography, Vol. 33, Pergamon, 161-200.

Schlosser, P., and Coauthors, 1997: The first trans-Arctic ${ }^{14} \mathrm{C}$ section: Comparison of the mean ages of the deep waters in the Eurasian and Canadian basins of the Arctic Ocean. Nucl. Instrum. Methods, 123B, 431-437.

Timmermans, M.-L., C. Garrett, and E. Carmack, 2003: The thermohaline structure and evolution of the deep waters in the Canada Basin, Arctic Ocean. Deep-Sea Res., 50A, 1305-1321.

—, P. Winsor, and J. A. Whitehead, 2005: Deep-water flow over the Lomonosov Ridge in the Arctic Ocean. J. Phys. Oceanogr., 35, 1489-1493.

Whitehead, J. A., A. Leetmaa, and R. A. Knox, 1974: Rotating hydraulics of strait and sill flows. Geophys. Fluid Dyn., 6, 101-125.

Woodgate, R. A., K. Aagaard, R. D. Muench, J. Gunn, G. Björk, R. Rudels, A. T. Roach, and U. Schauer, 2001: The Arctic Ocean boundary current along the Eurasian slope and the adjacent Lomonosov Ridge: Water mass properties, transports and transformations from moored instruments. DeepSea Res., 48A, 1757-1792. 